\title{
Communicating content: development and evaluation of icons for academic document triage through visualisation and perception.
}

\author{
Aekaterini Mavri, Cyprus University of Technology, Fernando Loizides, University of
}

Wolverhampton, Evripides Zantides, Cyprus University of Technology

Word count: 6,230 (excludes table data and bibliography)

\begin{abstract}
This work seeks to identify key features and characteristics for the design of icons that can support the tasks of information seekers in academic document triage interfaces. Such icons are meant to act as visual links to the specific elements or sections in an academic document. We suggest that icons in triage interfaces, are better able to communicate information, provide feedback and enable faster user interactions than text, particularly in mobile-based interfaces. Through investigation of visualisation and perception processes, we are able to propose five primary icon categories, the two most dominant being iconic and symbolic: iconic representations mostly apply to graphically and spatially distinct document elements (i.e. Title, Abstract, Tables and Figures) externalising the elements' surface propositions. Symbolic representations are largely associated with elements of greater semantic value (Introduction, Conclusion, Full text and Author), drawing upon the elements' deep propositions.
\end{abstract}

Aekaterini Mavri - (corresponding author) - aekaterini.mavri@cut.ac.cy

Cyprus Interaction Lab, Multimedia and Graphic Arts, Cyprus University of Technology, 30

Archbishop Kyprianou Str. 3036 Limassol, Cyprus. Telephone +357 25002130 - Fax +357 2500

2750

Fernando Loizides - fernando.loizides@wlv.ac.uk

Emerging Interactive Technologies Lab, School of Maths and Computer Science, Faculty of Science and Engineering, University of Wolverhampton, Wulfruna Street, Wolverhampton, WV1 1LY, UK.

Tel: 01902321000

Evripides Zantides - evripides.zantides@cut.ac.cy

Semiotics and Visual Communication Lab, Department of Multimedia and Graphic Arts, Cyprus

University of Technology, 30 Archbishop Kyprianou Str. 3036 Limassol, Cyprus. Telephone +357 25 $002314-2223$

\section{Keywords}

Icons, interface design, visual representation, academic document triage, visualization, perception 
Academic document triage is defined as the act of assessing and evaluating a set of structured documents in order to determine their relevance to an information need (Loizides 2010). This process has been exponentially increasing in the past years due to the digital access of journals by academics and professionals such as patent examiners. Because of the vast amount of information, made available with online digital libraries, document triage is a demanding, time-consuming and error-prone (Jones et al. 1999) process for information seekers. Existing research provides some information on designing usable triage interfaces mainly for desktop computers (Mavri et al. 2014); there is, however, minimal to no direction regarding small screen interfaces.

Tablets and smartphones have emerged as vital for information seeking and communication 'on the go', as statistics indicate about $60 \%$ of adults using a smartphone to go online (Ofcom 2015). The content of most websites and applications is largely adaptive in order to accommodate for the smaller screen real estate. However, some interfaces fail to provide the information seeker with an interface that addresses his/her specific needs, for example, when a user is working with large amounts of text, as in structured documents (i.e. academic documents). Both structure and content can be problematic, due to the known limitations of mobile devices, the most important being the limited screen size that results in small-sized characters, narrow line length and compromised navigation (Ling and Van Schaik 2006; Budiu 2015; Nielsen 2011; Sahito et al. 2015). Wishing to read specific sections in an academic document (a common triage behaviour), equals scrolling through thousands of words) (Loizides and Buchanan 2009); panning on a mobile device, can become physically strenuous, and scroll acceleration is frustrating, since it impedes reading of individual section titles on a mobile device. Getting from point A to point B, by means of anchoring (linking) 
information segments through hyperlinks, in a 'table-of-contents' style, may be a solution to this problem (Chakrabarti, Dom, and Indyk 1998).

Additionally, during information seeking within large structured documents, users need to rapidly assess results against specific information needs. In small scale devices, where attention and often time are compromised, speed and efficiency is paramount. Icons can therefore expedite this process, by communicating a message through faster comprehension, visual appeal, and improved usability and interaction (Ware 2010; D. A. Norman and Nielsen 2010; Isherwood and McDougall 2007; Lodding 1983; Gatsou, Politis, and Zevgolis 2012) So far, there has been limited knowledge on the factors that influence icon appropriateness within a broad context (Blankenberger and Hahn 1991). It is difficult to propose icons that are equally identifiable, in terms of ecological perception, as many factors influence the perception of icons, different intentions, attitudes and cultural characteristics for example (Huang, Huang, and Yu 2011; Syarief et al. 2003; Khanom et al. 2013). Furthermore, the interpretation of meaning may be compromised if an icon is separated from any contextual indicators (McDougall and Curry 2004). Interestingly, several studies denote, that icon identifiability and comprehensibility only become possible, within a particular context; icons begin to make sense - based on purpose - that is - desired tasks can be associated with the respective icons by users (Siau 2005; Rogers 1989; Isherwood and McDougall 2007; Sassoon and Gaur 1997; Huang, Huang, and Yu 2011; Sanders and McCormick 1987; Honeywill 1999).

This study does not claim ecological validity by aiming to produce a wide-ranging methodological framework for the systematic design of icons. Research claims that even the simplest and most limited design and evaluation models can have conflicting advice, when applied in different domains (Gittins 1986). Like similar work (Gittins 1986; Huang, Huang, 
and Yu 2011; Galitz 2007; Marcus 1984; McDougall and Curry 2004; Gatsou, Politis, and Zevgolis 2012; Tognazzini 1992; Preece et al. 1994; Rogers 1989), we take a small step by attempting to find attributes that can enhance icon communicativeness and effectiveness within this specialized field.

The design of icons in academic document triage (ADT) interfaces has not been thoroughly researched. By conducting a representative user-participatory study, we seek to collect and analyse realistic data through a. icon visualization and b. icon perception methods. In doing so, this study aims to:

1. Form an understanding of the appropriate types of icons (i.e. iconic, symbolic, indexical) - to act as quick-links to the individual sections/elements of a document, during ADT mainly for mobile devices.

2. Identify key design characteristics and features for icons that effectively support the tasks of information seekers within ADT interfaces.

The next section investigates literature in the areas of visual perception, mental imagery, visual representation and icon design. 'Study design' outlines the experiment, followed by an analysis of the results produced during the study (visualization and perception parts). The 'Discussion and guidelines' section states the outcomes and presents a design framework for ADT icons. Finally the Conclusion summarizes this work and describes future research directions. 


\section{Related work}

The application context of our study is Academic Document Triage, a highly visual process that users engage in to determine the relevance of a source to an information need (Loizides and Buchanan 2009). Understanding visual information processing and perception theories while investigating Human Computer Interaction (HCI) principles for the design and evaluation of icon-based interfaces, are necessary. For this reason we present the reader with a foundation on both icon theory and visual understanding/information assimilation and interaction concepts. We begin this section by examining the advantages of icon-based interfaces.

Researchers suggest that icons communicate meaning more effectively and help recipients make faster inferences than text (Ware 2010). 'The activation of meaning from an image, generally occurs in a small fraction of a second'; much less than what it takes to read text. This occurs since we utilize an inner 'perceptual resource pool', as opposed to employing cognitive activity, in the case of text (Gittins 1986; Lodding 1983; Benbasat and Todd 1993). An icon's mission in a digital environment is to capture users' attention and help them get information more quickly (Yan 2011; Mack et al. 2002). In fact, not only is it effective in helping users understand the functions they represent, but also in memorizing them (Siau 2005). The superiority of visual-over-verbal memory is well known: icons and metaphorbased cues in graphical user interfaces can convey and instil richer information than text. The most challenging task for designers is to effectively convey an icon's meaning (Gatsou, Politis, and Zevgolis 2012). Yet, Siau (2005) argues that designers cannot investigate this, away from the application context, which an icon is intended for.

Several models of visual theories exist, amongst which is Peirce's 'Theory of Signs' (Deledalle 2001) - which proposes a triadic icon/sign structure; namely, a sign: i.e. the icon 
of a door, an object: i.e. the door and an interpretant: the signified meaning from the objectto-sign relationship (Liszka 1990). In addition to the above, Marcus (Marcus 1984) proceeds to propose the following types of computer graphics/icons:

(a) Iconic: icons with direct resemblance to the object they represent (i.e. picture of a book). The degree of resemblance is also known as icon concreteness (Isherwood and McDougall 2007)

(b) Indexical: icons in the form of a 'cause and reaction' relationship: (i.e. smoke signifies fire)

(c) Symbolic: icons that are 'arbitrary in appearance' and become familiar only by means of learning and repetition) (pp616). Most of written/spoken language is considered to be symbolic (Gains 2013; Chandler 2007).

Iconic images are also known to be of surface propositional value, while both types, Indexical and Symbolic, carry deeper layer propositions ( 'underlying' connotations) (Lidwell, Holden, and Butler 2010). A lot of symbolic icons are known to be universally understood by means of convention. Examples of these are the 'prohibition', 'recycling', 'biohazard' ,'radiation' or the ISO 'emergency exit', 'electricity' or 'no smoking' icons, to list a few (ISO 2007). On the contrary, the majority of interface icons to date, are iconic and carry surface propositions, since they are mainly associated to real-world objects i.e. files and folders (Gittins 1986). Various studies attempt to provide classification schemas, design guidelines and usability factors (Galitz 2007; Marcus 1984; Yan 2011; Isherwood and McDougall 2007) for icons in HCI (system, desktop, application, windows and toolbar environments). Firstly, two major categories of icons are defined as: data icons, representing data objects (i.e. files and folders) and function icons, representing actions to be done; i.e. 'scissors' for cutting an 
element - an 'eraser' for removing something and so on (Rogers 1989; Lidwell, Holden, and Butler 2010).

Designing icons is challenging as they can be vague and may represent a number of different things (Galitz 2007). A list of factors that determine icon perception and usability are offered by Marcus in his work in Computer Graphics (Marcus 1984): familiarity, clarity and legibility, simplicity, consistency, directness, efficiency, discriminability. 'Context of use' is also added, since it can attribute special meaning to icons and "expedite user understanding, learning and recall"; the ambiguity of meaning behind an icon can be narrowed down by the context in which it is displayed (Rogers 1989). A similar argument is provided by Norman (D. Norman 1988), who explains that the affordances of an object (icon) are the properties that determine how it can be used. Norman discerns that these vary, based on the users' perceptual context, as well as prior knowledge and experiences. Mis/interpretation of affordances can occur based on the user's understanding, degree of computer literacy and level of application domain knowledge (i.e. document triage) (Siau 2005). A solid contextual environment is known to enhance user performance and researchers cannot examine icon characteristics in isolation of contextual factors (McDougall and Curry 2004; $\mathrm{Ng}$ and Chan 2008). The intended tasks determine the inferences that users make upon encountering an icon (Rogers 1989). Information seekers, in digital library applications, for example, can recognise an icon's function, based on the nature of their research i.e. to skim through results and scrutinize key paper sections.

Context is particularly important in graphical user interfaces with functionality that does not - necessarily - have obvious pictographic equivalents (Gittins 1986). What happens, for example in the case of an icon "such as a sheet of paper standing for a text file" - a concept distant of a concrete image (Blankenberger and Hahn 1991)? Studies have indicated the 
difficulty in designing icons for abstract concepts (Stammers and Hoffman 1991) and suggest that investing on 'semantic distance' (the amount of closeness between the icon and the function it represents within a system) is a more effective approach in such cases (Isherwood and McDougall 2007). From a visual point of view, Isherwood et al remark that such icons tend to include shapes such as arrows and lines to communicate the intended meaning. Context, in terms of medium or device, is also an important factor to take into consideration. From an interaction perspective, icons on small-screen devices can counteract the 'read-to-tap asymmetry' problem: a phenomenon, whereby text is large enough to read and small enough to miss with fingertips, such as the difficulty of textual hyperlinking (Nielsen 2010).

Conversely, 'icons make good targets: they are typically sized large enough to be easily touched in a finger-operated UI' (Bedford 2014). If designed effectively, they can econimise valuable space, concisely describing complex concepts and actions (Gatsou, Politis, and Zevgolis 2012). However, designing for effective icon-to-user communication is particularly important in regards to mobile devices, as factors such as display size, resolution and screen lightness can affect the perception of an icon's meaning.

\section{Study design}

The purpose of the study is to investigate the characteristics and affordances of icons that can represent the various elements and sections of an academic document, based on:

1. How participants visualize these sections/elements

2. How participants interpret icons in relation to these sections/elements

Both visualization and interpretation were deemed important and based on a within-subjects model, they were used as triangulation and concurrent validity measurements (Cohen, Manion, and Morrison 2013). The survey was thus divided in two parts: 


\subsection{Part 1: visualization}

Twenty participants were asked to digitally draw and explain -in writing- how they visualized specific elements in an academic document, for a total of 11 elements: title, author(s), keywords, abstract, introduction, section headings, full text, conclusion, figures, tables and references. An example of the first survey question follows below:

'Describe what you would draw to visually represent 'TITLE' in an academic document to others. Please explain your answer.' 'Please feel free to draw your idea below'

The interface presented two sketching tools, a pen (for contours) and a colour picker, as well as three predefined shape tools : circle, rectangle, straight line.

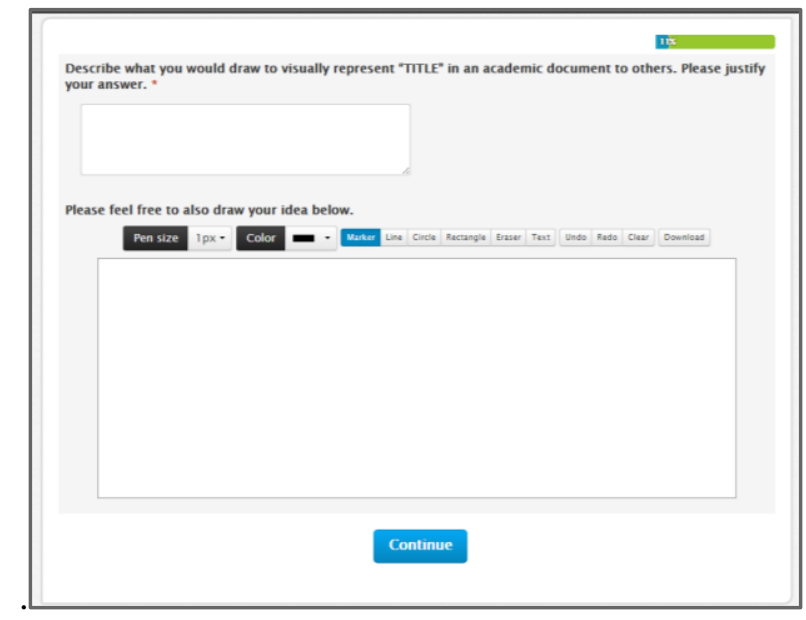

Figure 1. Part 1 of survey: Text description and drawing interface

\subsection{Part 2: interpretation}

Participants were asked to rate the relevance of a set of images against the elements in an academic document, on a one-to-five bipolar preference response scale ${ }^{1}$, with one being Very

\footnotetext{
1 'bipolar' is a scale providing a neutral mid-point while the two ends of the scale are the exact opposites (Schaeffer and Presser, 2003)
} 
Representative and five being Not Representative (Figure 2). The 11 elements were drawn as icons by five professional Visual Communication designers and five HCI scientists - all with experience in academic documents. Both groups were expected to employ different visual thinking processes and produce different genres of icons, to be interpreted by the diverse participant sample in the study.

A total of 110 icons, organized by element in tables were presented (Figure 2). The preference results were to be quantitatively analysed to derive the most representative iconsper-element. Researchers also categorized each icon by type, (based on aforementioned semiotic and graphic guidelines) for comparing against visualization results from study partone.

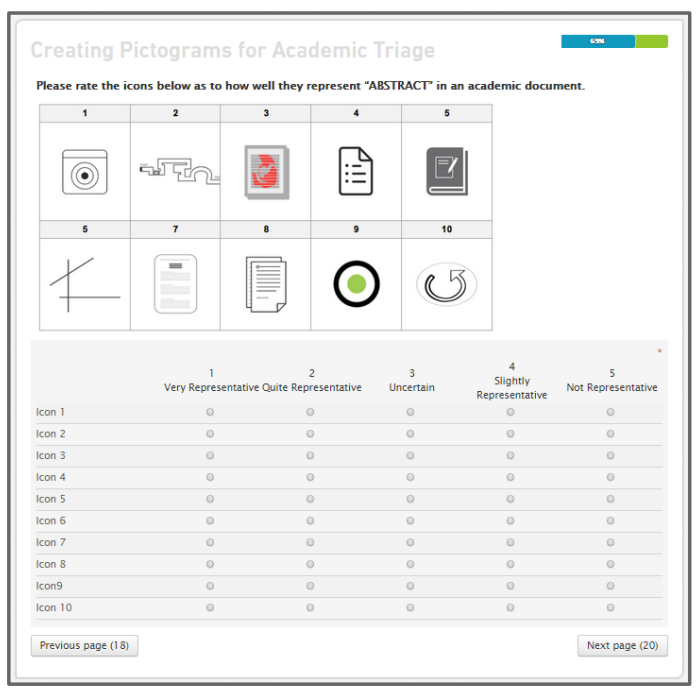

Figure 2. Part 2 of survey: Image-to-element match rating

\subsection{Participant sampling}

Candidates were:

1. Researchers or Scholars, with experience in information seeking for large structured documents (academic or scientific publications) 
2. Originating from a diverse range of academic disciplines

Point 2 was important so that wide-ranging data was collected. A participant pool from different disciplines guaranteed enhanced ecological validity for the results. According to the Joint Academic Coding System (HESA 2003) used by the Higher Education Statistics Agency and the Universities and Colleges Admissions Service (UCAS), there are approximately 20 major classifications for academic disciplines (Annex A: Table A1). Candidates were invited to participate via email. An introduction into document triage, the purpose of the experiment, participation instructions and an inform/consent form were presented to participants. Basic ethnographic data (gender and age range) were also required. Participants were also asked to provide contact details for brief follow-up interviews.

\section{Analysis of study part 1: Visualization}

'I think in pictures. Words are like a second language to me.' (Grandin 2010)

Data from the online survey, part one (open-ended questions) as well as follow-up interviews were analysed in nVivo ${ }^{2}$. Two (out of three) researchers went through the dataset several times independently, in order to identify emerging codes (Braun and Clarke 2006). An inductive thematic analysis approach was followed; the researchers did not have a predefined coding frame based on theoretical or epistemological interests. Following saturation, the two researchers discussed, refined and agreed on the final code structure, a group of 13 codes in total. A report on the code structure and descriptions was provided to a third researcher in order to also classify the data. At the same time, one more researcher went through the same procedure, separately. An approximate $10 \%$ subsample of the coded data

\footnotetext{
${ }^{2} \mathrm{NVivo}$ is a qualitative data analysis (QDA) computer software package produced by QSR International (Wikipedia)
} 
was examined for inter-rater reliability using Cohen's kappa coefficient with a produced a

result of $\kappa=0.6$ (moderate to well degree of agreement).

Table 1. Refined theme/coding structure

\begin{tabular}{|c|c|c|}
\hline & Code & Description \\
\hline 1. & Size-scale & (i.e. 'big', 'large', 'larger' than...) \\
\hline 2. & Fonts-Typography & Typeface, weight, style, general treatment \\
\hline 3. & Colour & \\
\hline 4. & Layout - positioning & Alignment, positioning ('top', 'bottom', 'below' etc), justification of elements \\
\hline 5. & Writing-content & Text, words, letters, symbols and numbers \\
\hline 6. & Document resemblance & $\begin{array}{l}\text { Elements that resemble the original paper structure i.e. 'paragraphs', 'columns' } \\
\text { etc. }\end{array}$ \\
\hline 7. & Emphasis-importance & References in regards to attention, prominence, significance of an element. \\
\hline 8. & Information scent & $\begin{array}{l}\text { References that describe an element that provides a good picture (at first sight) of } \\
\text { what follows (like a cut-down version) }\end{array}$ \\
\hline 9. & Shapes-lines-objects & Abstract drawings, elements \\
\hline 10. & Conceptual drawings & Specific drawings (e.g. 'ball', 'house' etc.) with specific connotations \\
\hline 11. & Personalization & $\begin{array}{l}\text { References that are discipline-specific or based on the scientific understanding of } \\
\text { the individual }\end{array}$ \\
\hline 12. & Comparison & Evaluation against other elements in the document (e.g. 'unlike the abstract'....) \\
\hline 13. & Simplistic & Any references to minimal, simple, basic elements/design \\
\hline
\end{tabular}

Following the coding phase, data was reduced to five thematic groups. In specific, categories were identified by means of reference coverage as presented in Table 2 .

Table 2. Major thematic categories

\begin{tabular}{llllll}
\hline \multicolumn{2}{l}{ Major thematic categories: coding references occurrence } \\
$\begin{array}{lllll}\text { 1. Iconic } \\
\text { representations }\end{array}$ & $\begin{array}{l}\text { 2. Iconic } \\
\text { representations } \\
\text { with symbolic } \\
\text { meaning }\end{array}$ & $\begin{array}{l}\text { 3. Iconic } \\
\text { representations } \\
\text { through visual } \\
\text { homonymy }\end{array}$ & $\begin{array}{l}\text { 4. Representations } \\
\text { with linguistic } \\
\text { aids }\end{array}$ & $\begin{array}{l}\text { 5. Abstract and } \\
\text { deictic } \\
\text { representations }\end{array}$ & 6. Other \\
\hline $43,3 \%$ & $21,8 \%$ & $2,7 \%$ & $21,8 \%$ & $6,1 \%$ & $4 \%$ \\
\hline
\end{tabular}


(a) Iconic representations. Signs (drawings and text descriptions) that have direct visual resemblance to their referent objects, in this case, the object is the document itself. The surface propositions (Benbasat and Todd 1993) were based on simplistic schematic drawings, by means of position, layout, size/scale and typographic characteristics: i.e. a rectangular shape indicating the Abstract, appears below three other rectangular shapes of (smaller) varying heights, indicating the Title, Author and Keywords elements (Figure $3)$.

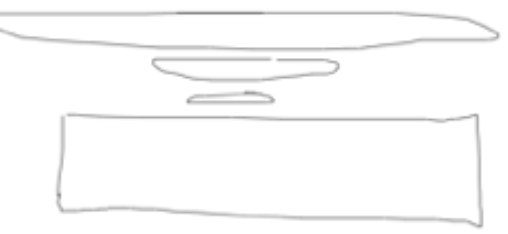

Figure 3. Iconic representation example for the Abstract Element

(b) Iconic representations with symbolic meaning (iconic-symbolic). Signs (drawings and text descriptions) that have direct visual associations to real-world objects, yet, they carry deep propositional value (underlying meanings) usually associated with abstract notions or actions (Lidwell, Holden, and Butler 2010): i.e. a house and door represent the Title element, signifying the entrance to 'a world of knowledge' (Figure 4).

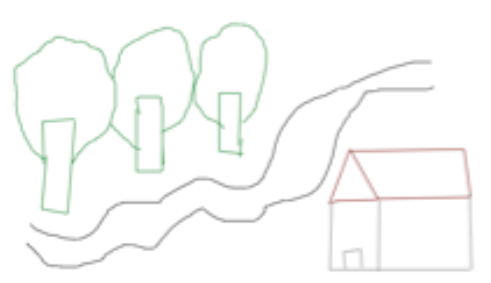

Figure 4. Iconic Representation with symbolic meaning example for the introduction element 
(c) Iconic representations through visual homonymy. Homonymy indicates that two words are identical in writing and pronunciation, yet, different in meaning. Visual homonymy, within the scope of this study, refers to an icon that represents the homonym's signifier a real-world object - rather than the concept it represents, as this level of abstraction is hard to illustrate: i.e. a key for the Keywords element (Figure 5) (the first word is the dominant identifier).

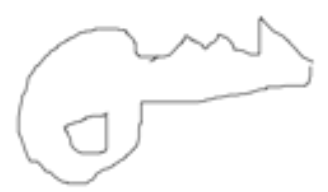

Figure 5. Iconic Representation through visual homonymy example for the keywords element

(d) Representations with linguistic aids. Drawings and text descriptions that incorporate the use of words, letters, numbers and symbols to convey meaning: i.e. a drawing with bracketed numbers representing the References (Figure 6).

\section{[1] \\ [2] \\ $[3]$}

Figure 6. Representations with linguistic aids example for the references element

(e) Abstract and deictic representations. These refer to icons that have no association to real-world objects. They consist mostly of non-figurative visuals with plain lines or shapes, sometimes combined with arrows, meant to connote the underlying values of elements: i.e. a set of arrows pointing inwards towards a circle, implying the focal point for the Conclusion (Figure 7). 


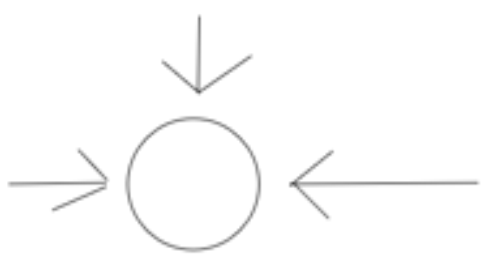

Figure 7. Abstract and deictic representations example for the Conclusion element

(f) Other. All other signs (mainly text descriptions) in the form of personalized comments, ideas and beliefs in regards to the elements in an academic document.

\subsection{Iconic representations}

For the purpose of this study, we defined iconic as direct representations of the document itself, as the referent object. A large part of the results $(43,3 \%)$ fell into this category. Although literature associates iconic signs with actual, physical elements (Benbasat and Todd 1993; Lodding 1983), we can also infer that this association is also applicable for elements that bare no such 'concrete image' associations (Blankenberger and Hahn 1991).

What participants were required to do was not simple; they were asked to visualize, draw and explain abstract elements. The contents of an academic paper are non-tangible, threedimensional objects; they are virtual entities on paper. Nevertheless, externalized visuals were produced illustrating surface propositions (Benbasat and Todd 1993) through attributes such as form, size, position, layout and formatting (Table 3). Realistic iconic representations can therefore exist, in terms of 'where' and 'how' elements appear in a two-dimensional space. A list of perceptual 'specifiers', for extracting visual information (Liu, Salvendy, and Kuczek 1999) applicable within the context of this study, appears in sections 3.1.1 and 3.1.2 below. 
Table 3. Iconic representations - surface propositions reference coverage

\begin{tabular}{cccccc}
\hline Spatial: position & $\begin{array}{l}\text { Spatial: } \\
\text { form - layout }\end{array}$ & $\begin{array}{l}\text { Formatting: } \\
\text { density }\end{array}$ & $\begin{array}{l}\text { Formatting: } \\
\text { size - length }\end{array}$ & $\begin{array}{l}\text { Formatting: } \\
\text { size - volume }\end{array}$ & Other \\
\hline $22 \%$ & $21.1 \%$ & $31.7 \%$ & $8.2 \%$ & $8.2 \%$ & $8.2 \%$ \\
\hline
\end{tabular}

\subsubsection{Spatial representation (position, layout/form)}

In this study participants mainly sketched and described the elements and sections relying heavily on position and proximity to others, in the two-dimensional region. They also justified their decisions accordingly; the abstract appears right below the Title and Author sections and participants drew it exactly like that (Annex B: Table B1) as they argued it was too hard to illustrate its semantic values (meaning/importance). Instead the paper boundaries and spatial relation to other elements (i.e. hierarchy/order), were easier to illustrate in order to aid cognition. The shape and layout of information, as seen from a deductive schematic aspect, were used as visual indicators of the element's identity (Annex B: Table B2).

\subsubsection{Formatting representation (density, length, volume)}

The analysis of iconic representations also asserts that such abstract entities can also be communicated, by means of formatting characteristics - mostly typographical - employed in varying degrees to denote similarity and/or contrast. Signifiers like ' density', 'volume' and 'length' were extensively used to communicate meaning. Amongst others, these are commonly used in design practice to convey information (Liu, Salvendry, and Kuczek 1999).

Density (line weight). We refer to density as the line weight (thickness), used to indicate three typographic attributes in the study: scale (font size), style (bold, italic, caps) and emphasis 
(focusing on a specific point). Title and Section Headings received this treatment, for example, in contrast to Full Text which appeared in plain, thin lines (Annex B: Table B3); the differences and similarities among elements, based on both the existence and absence of such signifiers, were explicitly presented, otherwise meaning could not be conveyed, participants explained.

Length. Small line segments indicated shorter sections such as Keywords for example; longer lines indicated the Full Text section. These, combined with alignment and layout configurations, suggested particular document elements (Annex B: Table B4). Volume. The amount of lines (usually enclosed within a block) acted as a key-identifier in a number of drawings. Depending on how many and how (vertically) condensed they appeared (leading), these did not only indicate an element's size, but its 'semantic importance' within the paper as well (Annex B: Table B5).

\subsection{Iconic representations with symbolic meaning (iconic-symbolic)}

This study indicates that over one-fifth of visual interpretations $(21,8 \%)$ were iconicsymbolic. These were visually disassociated from their referent objects - that is, the document itself or the document elements and sections. Participants proposed a set of fictional images and occasionally incorporated them in narrative visuals in order to communicate their identity. They explained that most of these elements were 'hard to represent or even to think of how to visualize'. Existing research supports that abstract concepts are indeed 'resistant to representation' by means of simple imagery.

In an effort to infer meaning from these iconic-symbolic representations, an 'icon-tomeaning' association framework was required. Such was found in the Archetypal index 
(Macnab 2011; Lidwell, Holden, and Butler 2010). Literature describes archetypes as original mental models, unconsciously inherited and embedded into our brains, over the course of human evolution, regardless of time and culture.

The following sections present and analyse the iconic symbolic patterns that have emerged from this study.

\subsubsection{Anthropomorphic representations: human body, face and apparel}

A number of iconic-symbolic visualizations included anthropomorphic forms or human body part(s) and related items. These are visuals that take on a human form, in accurate or 'reduced-to-basics' approach. Our tendency to visualize faces, bodies and related parts, in various objects, is evident in all art, literature, mythology and in fact, everyday life. As anticipated, these drawings were primarily used to represent the 'Author/s' section in the academic document. Some of these are purely iconic, as they directly depict their signifiers (i.e. the figure of a real person) (Annex B: Table B6); the rest are symbolic, in the sense that they attempt to connote deeper propositions and qualities (intellectuality and wisdom) (Annex B: Table B7).

Specific parts of the body (i.e. a hand holding a pen), facial characteristics and external apparel (i.e. glasses, well-fit costumes, hat) were chosen in terms of their relevance to the act of authoring as well as intellectual ability and knowledge (Lawrence 1998). They were also meant to convey status: knowledgeable, respected, wise, spiritual, just (preacher, poet, judge, gatekeeper, teacher). Interestingly, a similar character from the archetypal theory is that of the 'wise old man' or 'hero' archetype (Bakhysh 2012; Hartwell and Chen 2012). In 
this study, there was limited visual output, due to the complexity of this drawing task, but respective descriptions are presented in Annex B: Table B8.

\subsubsection{The house and tree archetypes}

The Archetypal theory provides associations between the house and the human body (or soul) and the analogy extends by outlining connections between the upper parts of the house (e.g. the attic) and the human brain, spirit and the mind (Gieseking et al. 2014; Petocz 1999). Interestingly, similar correlations surfaced in this study in relation to the academic document: i.e. 'doorsteps' for introduction, 'doors inside the house' for the document sections and 'windows' for references. Additionally, the concept of the mind as the 'house of thoughts', ' $a$ space of knowledge', is prominent (Annex B: Table B9).

Various drawings also include relevant objects such as trees and produce (Annex B: Table B10) as icons: the garden, the trees, the fruits, the juice, all intend to illustrate 'fruitful knowledge'. The apple - a prominent figure in the drawings of the study - also seems to refer to the scientific, due to its relation to Newton's gravity theory (Ferber 2007). It is implicitly linked to thought and knowledge: a bite from the apple or distilling the produce signifies the attainment of knowledge and meaning.

It is important to note that all examples of iconic-symbolic representations share a common characteristic: a framework (i.e. 'The apple tree, house and hill scenery'), which is established early on in the experience, for one to make meaningful inferences as to the identity of the individual parts. Participants explained that meaning could not be derived in isolation from a thematic context. 


\subsection{Iconic representations through visual Homonymy}

In a few cases, participants used icons of objects that were homonymous to the represented elements (Annex B: Table B11). Homonyms are defined as two words with identical spelling and pronunciation, yet they carry different meanings (Ferber 2007). Existing evidence too, indicates that visual representations of abstract elements often rely more on 'verbal associative processes' to communicate the intended meaning (Knight, Gunawardena, and Aydin 2009). The choice of such - phonetically matching - but - visually different - drawings was evidently twofold:

(a) The verbally associated objects were easier to draw as they depict real-world equivalents (i.e. a key for 'keywords') (Libby and Eibach 2013).

(b) They were occasionally used metaphorically, for their deep propositional values; i.e. a $k e y$, as a component for accessing document information, opening the door of 'knowledge'.

\subsection{Representations with linguistic aids (letters, numbers and punctuation)}

One tenth of the produced drawings in the study incorporated some form of written aids. Participants resorted to verbal aids, in order to clarify the meaning of their drawings (Sadokierski 2010; Ware 2010). Letters, numbers and punctuation (exclamation marks, brackets, bullet points, parentheses) were added in order to make up for the ambiguity of simple lines and scribble (Annex B: Tables B12 and B13). Exclamation marks were used semantically - to direct attention and attach a linguistic tone of importance to an element (stylization) (Waller 1980). Brackets or parentheses were used to isolate segments and draw 
attention to elements within larger text structures (delineation).

\subsection{Abstract and deictic representations}

Drawings with no iconic/visual resemblance to their referents or real-world objects, were labelled as abstract. These include arbitrarily designed shapes, lines and dots that may serve as strong aids for depicting complex visual and symbolic information, if used creatively (Ware 2010; Macnab 2011). Their vagueness can, however, generate a number of interpretations, as demonstrated in Table 4.

Table 4. Shapes and lines in ambiguous interpretations

\begin{tabular}{|c|c|c|c|}
\hline Sign & Interpretant & Sign & Interpretant \\
\hline & Waves & & Sun \\
\hline & Thunder & & Ball \\
\hline & Electricity & & Ring \\
\hline & Mountain & & Hole \\
\hline & Ice & & Coin \\
\hline & Earthquake & & Button \\
\hline
\end{tabular}

Comments suggested that the circle was chosen because of its capacity to symbolize distinct concepts: a central or focal point of reference, the concentration of information as well as the notion of continuity (Annex B: Table B14). The square, which was evidently used to imply notions of solidness and completeness and the enclosure of ideas and concepts (Annex B: Table B15). Finally, lines were used in order to illustrate direction, movement, to join shapes and to enclose other information (Annex B: Table B16). 
Table 5. Abstract shapes percentage coverage (some overlapping occurs)

\begin{tabular}{lll}
\hline Circles & Rectangles & Lines \\
\hline $57,2 \%$ & $23,1 \%$ & $20,1 \%$ \\
\hline
\end{tabular}

Approximately half (51\%) of these drawings also incorporated arrows in corresponding drawings (Annex B: Table B17) to indicate direction and flow of information or to focus on a specific point. Arrows were also used to lead towards an outcome or to finalize things (i.e. pointing to the right or downwards). Deictic components are widely employed, in sketching and design, either to demonstrate sequences of events or to depict semantic relationships between elements - an effective pattern-interpretation system that participants also utilized (Ware 2010).

\section{Analysis of study part 2: Perception}

In part two of the study, participants were asked to rate the relevance of icons against the eleven elements in an academic document, on a one-to-five preference response scale, with one being Very Representative and five being Not Representative. The results are categorized as follows (Table 6).

Table 6. Rating ranges

\begin{tabular}{ll}
\hline Positive ratings values & $1-2.55$ \\
\hline Neutral ratings values & $2.6-3.55$ \\
\hline Negative ratings values & $3.6-5$ \\
\hline
\end{tabular}

By analysing the significantly preferred visuals, dominating parameters were identified in their composition. The majority of these were iconic. 
Particularly, from the 110 icons suggested to the participants, 12 were accepted (Annex B: Table B18) with an average score of one or two (following round-down to the nearest integers) and selecting the ones with a mean value below 2.5 as well as a mode of either one or two. A total of 56 drawings were found to be neutral (Table 7).

The remaining 43 were negatively rated by participants with an average score of three to four, an average mean value above 3.5 and a mode of four or five (Annex B: Table B19). The preferred icons were presented graphically, with emphasized lines (using colour and width/weight/length) in the expected position of various sections in an academic document (Title, Author, Keywords, Abstract, Introduction, Headings, Full-text, Conclusion and References). Additional dominant visual variables employed in these were: different values of light versus dark, as in brightness to create emphasis, different colours but only among two (black, warm red and successive values) also for emphasis, horizontal orientation, layout and rectangular shapes mainly with circular corners. Icons for Figures and Tables were also understood as they noticeably resembled their document equivalents.

Interestingly, there were no abstract or iconic-symbolic drawings preferred by the participants, nor linguistic - in typographic terms (i.e. the word title out of the letters T, I, T, L, E). A major advantage that derives from the absence of linguistic text is that it suggests an international graphic language where letters, like in the case of vehicle and road signs, are not necessarily present in the visual communication (Boada 2014). 
Table 7. Significant acceptance rating percentages by element $(n=<2.5, S D=<0.15$, ode $=1$ or 2$)$

\begin{tabular}{|c|c|c|c|c|c|}
\hline $\begin{array}{l}\text { Document } \\
\text { Element }\end{array}$ & $\begin{array}{l}\text { 1. Iconic } \\
\text { representations }\end{array}$ & $\begin{array}{l}\text { 2. Iconic } \\
\text { representations } \\
\text { with symbolic } \\
\text { meaning }\end{array}$ & $\begin{array}{l}\text { 3. Iconic } \\
\text { representations } \\
\text { through visual } \\
\text { homonymy }\end{array}$ & $\begin{array}{l}\text { 4. Representations } \\
\text { with linguistic } \\
\text { aids }\end{array}$ & $\begin{array}{ll}\text { 5. } & \text { Abstract } \\
& \text { representations }\end{array}$ \\
\hline Title & $20 \%$ & $10 \%$ & - & $10 \%$ & $10 \%$ \\
\hline Author & $60 \%$ & - & - & - & - \\
\hline Keywords & - & - & $20 \%$ & $10 \%$ & - \\
\hline Abstract & $10 \%$ & - & - & - & - \\
\hline Introduction & $20 \%$ & - & - & - & - \\
\hline S. Headings & $10 \%$ & $20 \%$ & - & - & - \\
\hline Full text & $40 \%$ & - & - & - & $10 \%$ \\
\hline Conclusion & $20 \%$ & - & - & - & $10 \%$ \\
\hline Figures & $30 \%$ & - & - & - & - \\
\hline Tables & $40 \%$ & - & - & - & - \\
\hline References & - & $10 \%$ & - & - & - \\
\hline
\end{tabular}




\section{Discussion and guidelines}

Thematic and content analysis outcomes were presented separately for parts one and two of the study respectively. Tables 8 and 9 indicate the 'designers and HCI scientists' and the 'user-generated' icon results - organized by element and category.

Table 8. Percentage of designer-generated (Visual Communication designers and Human Computer Interaction scientists) icons by element and category

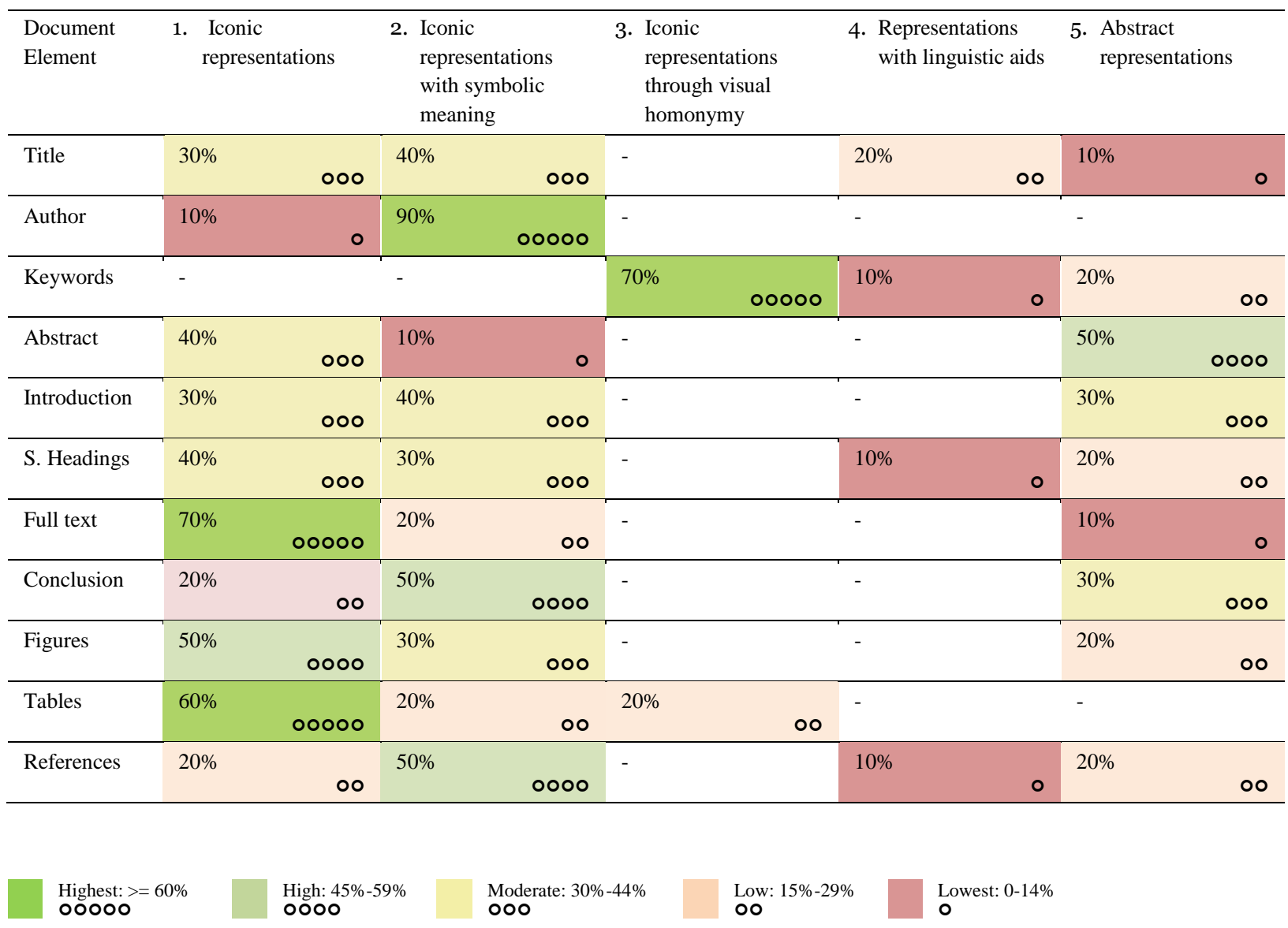


Table 9. Percentage of user-generated icons by element and category

\begin{tabular}{|c|c|c|c|c|c|c|c|c|c|c|}
\hline $\begin{array}{l}\text { Document } \\
\text { Element }\end{array}$ & \multicolumn{2}{|c|}{$\begin{array}{ll}\text { 1. } & \text { Iconic } \\
\text { representations }\end{array}$} & \multicolumn{2}{|c|}{$\begin{array}{l}\text { 2. Iconic } \\
\text { representations } \\
\text { with symbolic } \\
\text { meaning }\end{array}$} & \multicolumn{2}{|c|}{$\begin{array}{l}\text { 3. Iconic } \\
\text { representations } \\
\text { through visual } \\
\text { homonymy }\end{array}$} & \multicolumn{2}{|c|}{$\begin{array}{l}\text { 4. Representations } \\
\text { with linguistic aids }\end{array}$} & \multicolumn{2}{|c|}{$\begin{array}{ll}\text { 5. } & \text { Abstract } \\
& \text { representations }\end{array}$} \\
\hline Title & $50 \%$ & 0000 & $11,1 \%$ & 0 & - & & $16.6 \%$ & ০০ & $16.6 \%$ & ০০ \\
\hline Author & $21,5 \%$ & ০০ & $45,1 \%$ & 0000 & - & & $11,1 \%$ & 0 & $22,2 \%$ & ০০ \\
\hline Keywords & $33,3 \%$ & ০০০ & $11,1 \%$ & 0 & $27,7 \%$ & ০০ & $16,6 \%$ & ০০ & $11,1 \%$ & 0 \\
\hline Abstract & $27,7 \%$ & ০০ & $38,8 \%$ & 000 & - & & $11,1 \%$ & 0 & $22,2 \%$ & ০০ \\
\hline Introduction & $27,7 \%$ & ০০ & $61,1 \%$ & 00000 & - & & $5,4 \%$ & 0 & $5,5 \%$ & 0 \\
\hline S.Headings & $38,8 \%$ & ০০০ & $27,7 \%$ & ০o & - & & $22,2 \%$ & ০০ & $5,4 \%$ & 0 \\
\hline Full text & $32,3 \%$ & ০০০ & $45,3 \%$ & 0000 & - & & $5,4 \%$ & 0 & $16.6 \%$ & ০০ \\
\hline Conclusion & $21,1 \%$ & ০০ & $47,3 \%$ & 0000 & - & & $15,7 \%$ & ০০ & $15,7 \%$ & ০০ \\
\hline Figures & $55,5 \%$ & 0000 & $11,1 \%$ & 0 & - & & - & & $27,7 \%$ & ০০ \\
\hline Tables & $66,6 \%$ & 00000 & $22,2 \%$ & ০০ & - & & - & & $11,1 \%$ & 0 \\
\hline References & $20,1 \%$ & ০o & $39,8 \%$ & 000 & - & & $24,8 \%$ & ০० & $15,1 \%$ & ০০ \\
\hline $\begin{array}{l}\text { Highest: > } \\
\text { O०००० }\end{array}$ & & $\begin{array}{l}\text { High: } 45 \% \\
\text { ०००० }\end{array}$ & & $\begin{array}{l}\text { Moderate: } 30 \\
\text { ००० }\end{array}$ & $44 \%$ & $\begin{array}{l}\text { Low: } 15 \\
\text { ○० }\end{array}$ & & $\begin{array}{l}\text { Lowest: } 0-14 \% \\
\text { ○ }\end{array}$ & & \\
\hline
\end{tabular}

The results indicate that more obvious elements - in terms of position, layout or prominence were externalised as purely iconic representations. For example, the Title, isolated at the top of the document, could readily be illustrated through visual differentiation (variations of line weight and position) to other peripheral elements. The Tables and Figures elements (graphical elements) were expressed, based on their illustrative or schematic features. Their surface propositions (external characteristics) were communicated via direct iconic resemblance to their referent objects (document and contents).

Inversely, results indicate that elements with higher semantic prominence such as the Introduction, Conclusion, Full text and Author, were externalised mostly as symbolic-iconic or - to-a-lesser-extend - as abstract representations, drawing upon the elements' deep propositional values, to communicate identity. Interestingly, these information-heavy elements are also typically those that users seek in order to evaluate the relevance of a 
document against their research needs, during triage (Loizides 2010). This is also indicative for the References and Abstract elements, although iconic-symbolic drawings occurred slightly less for the last two.

The Section Headings, Keywords and Full Text elements were also partially communicated by means of spatial arrangement and layout (structure, proximity), as well as through variations of formatting attributes (line weight, line length, line volume, line density). Interestingly, these typographically distinct elements were also drawn utilizing punctuation in order to:

(a) Delineate (or mark) the area/segment that an element occupies, for example through square or curly brackets and quotation marks.

(b) Indicate serialized information, through bullets and numerals, like in the cases of Section Headings and References.

(c) Expose the significance of important elements by means of stylization aids like, for example, quotation marks (Waller 1980).

Finally, in certain cases, elements such as Keywords and Tables, were prominently illustrated based on their corresponding homonyms' surface propositions (such as a real key or a table for example), in order to avoid the ambiguity of abstract representations.

Based on the above, the design guidelines point to key indicators of the elements' identity in an academic document. These indicators may also be used in combination in order to promote accurate interpretation. 


\subsection{Design Guidelines}

Elements in an academic paper can be represented using spatial, formatting, linguistic and homonym properties as well as iconic-symbolic or abstract types of representations. These are summarized below and described in detail in Annex C: Table C2.

(a) Spatial properties

Elements can be represented:

- By means of position, through their distance from other peripheral elements as well as the paper boundaries.

- By means of form or shape.

- By means of layout, through the order in which they appear.

(b) Formatting properties

Elements can be represented:

- By means of density, for example employing different line thicknesses, to imply significance or the opposite, as well as direct/avert attention to/from a specific element in the document.

- By means of line length, to indicate the horizontal span of an element; for example, wider lines representing the full text element versus narrower lines, for the abstract. 
- By means of volume, for example more lines to indicate a large textual unit (i.e. full text)

(c) Linguistic aids

Elements can be represented:

- Through alphanumeric characters and punctuation, to complement illustrations. For example the initials of an element's name (a big ' $\mathrm{T}$ ' for 'title') or ascending numbers and bullet points next to horizontal lines to indicate serialized information (i.e. 'references') and help narrow down the interpretation possibilities.

- Through punctuation such as brackets, parentheses and exclamation marks, to either delineate an element from others in a document or to illustrate its importance.

(d) Visual Homonymy properties

Elements can be represented by depicting key visual characteristics of their homonyms, which are real-world, as opposed to abstract/semi-abstract objects (i.e. a key for 'keywords').

(e) Iconic representations

Elements can be represented drawing from archetypal forms to signify their deep propositions, through the depiction of surface propositions. Although iconic-symbolic representations can derive from a large number of conceptual themes, suggestions include the use of anthropomorphic forms and shapes as well as related apparel (i.e. 
face with moustache and glasses for 'author/s'). A consistent contextual framework must be present.

(f) Abstract representations

Elements can be represented through the use of basic shapes, for example, circles, squares or straight lines to imply conceptions of focus, continuity, stability, completeness and direction (i.e. a circle for the 'abstract' as the focal point of a document)

\section{Conclusion}

The aim of this work is to contribute to the production of assistive visual tools that can enhance information seeking and interaction in triage interfaces. Through this study, we were able to derive both physical and semantic characteristics that can guide the design of icons in order to support information seekers in the specialized field of academic document triage. Effective icon types - per element (iconic, iconic-symbolic, visual homonyms, linguistic and abstract) were identified (Tables 8 and 9) and a framework of design guidelines for ADT icons is presented in Section 5: 'Discussion and guidelines'.

This study is limited due to a restricted participant sample, both in terms of number and selection. Future plans aim to include a wider and more diverse audience in terms of location and culture, to target possible limitations in the understanding and interpretation of visual artefacts in ADT. This study does not claim ecological validity; what we are able to report on, in this article's work and through the outcomes of this study, are findings that contribute to design frameworks for the creation, employment and evaluation of interfaces for document 
discovery and searching through the effective use of icons (Section 5: 'Discussion and guidelines').

In order to meet the objectives of the study, we produced thorough grounding from previous related literature, and conducted studies to compliment the granularity of our framework (Section 1: 'Related work'). The results from both parts of the study indicate that the elements and sections of an academic document can predominantly be represented via iconic and iconic-symbolic images. In specific, iconic applies to elements with obvious surface propositions (Title, Section Headings, Keywords) as well as illustrative and graphically distinctive elements (Tables and Figures). Icons for more information-heavy, significant elements in the document (Introduction, Conclusion, Full text, Author) can also rely on semantic values (deep propositions) to communicate meaning symbolically. Such symbolic icons warrant a consistent conceptual framework, throughout ADT interfaces, to enable the interpretation of individual elements. Finally, homonyms (of real-world objects) can be used for icons - wherever applicable - to avert ambiguity of meaning (i.e. Keywords). 


\section{Bibliography}

Bakhysh, Savinj Horvath Izabella Geybullayeva Rahilya. 2012. Archetypes in Literatures and Cultures : Cultural and Regional Studies. Edited by Rahilya Geybullayeva. Peter Lang $\mathrm{GmbH}$, Internationaler Verlag der Wissenschaften.

Bedford, Aurora. 2014. "Icon Usability." Nielsen Norman Group Articles.

Benbasat, Izak, and Peter Todd. 1993. “An Experimental Investigation of Interface Design Alternatives: Icon vs. Text and Direct Manipulation vs. Menus.” International Journal of Man-Machine Studies 38 (3). Elsevier: 369-402.

Blankenberger, Sven, and Klaus Hahn. 1991. "Effects of Icon Design on Human-Computer Interaction.” International Journal of Man-Machine Studies 35 (3). Elsevier: 363-77.

Braun, Virginia, and Victoria Clarke. 2006. "Using Thematic Analysis in Psychology." Qualitative Research in Psychology 3 (2). Taylor \& Francis: 77-101.

Budiu, Raluca. 2015. "Mobile User Experience: Limitations and Strengths.” Nielsen Norman Group 19.

Chakrabarti, Soumen, Byron Dom, and Piotr Indyk. 1998. "Enhanced Hypertext Categorization Using Hyperlinks.” In Proceedings of the 1998 ACM SIGMOD International Conference on Management of Data, 307-18. SIGMOD '98. New York, NY, USA: ACM. doi:10.1145/276304.276332.

Chandler, Daniel. 2007. “The Basics: Semiotics.” London: Routledge.

Cohen, Louis, Lawrence Manion, and Keith Morrison. 2013. Research Methods in Education. Routledge. 
Deledalle, Gérard. 2001. View Larger Charles S. Peirce's Philosophy of Signs Essays in Comparative Semiotics. Indiana University Press.

Ferber, Michael. 2007. A Dictionary of Literary Symbols. Cambridge University Press.

Gains, Neil. 2013. Brand esSense: Using Sense, Symbol and Story to Design Brand Identity. Kogan Page.

Galitz, Wilbert O. 2007. The Essential Guide to User Interface Design: An Introduction to GUI Design Principles and Techniques. John Wiley \& Sons.

Gatsou, Chrysoula, Anastasios Politis, and Dimitrios Zevgolis. 2012. "The Importance of Mobile Interface Icons on User Interaction.” IJCSA 9 (3). Citeseer: 92-107.

Gieseking, Jen Jack, William Mangold, Cindi Katz, Setha Low, and Susan Saegert. 2014. The People, Place, and Space Reader. Routledge - Taylor \& Francis Group. http://peopleplacespace.org.

Gittins, David. 1986. “Icon-Based Human-Computer Interaction.” International Journal of Man-Machine Studies 24 (6). Elsevier: 519-43.

Grandin, Temple. 2010. Thinking in Pictures: My Life with Autism. Reissue. Vintage.

Hartwell, Margaret, and Joshua C Chen. 2012. Archetypes in Branding: A Toolkit for Creatives and Strategists. How Books.

HESA. 2003. Joint Academic Coding System (JACS). UK. https://www.hesa.ac.uk/dox/jacs/JACS_complete.pdf.

Honeywill, Paul. 1999. Visual Language for the World Wide Web. Intellect Books. 
Huang, Tien Chi, Yueh Min Huang, and Fu Yun Yu. 2011. "Cooperative Weblog Learning in Higher Education: Its Facilitating Effects on Social Interaction, Time Lag, and Cognitive Load.” Educational Technology and Society 14 (1): 95-106.

Isherwood, Sarah J, and Sin McDougall. 2007. "Icon Identification in Context: The Changing Role of Icon Characteristics with User Experience.” International Journal of ManMachine Studies 49 (3). Elsevier: 465-76.

ISO, I S O. 2007. “Standard Graphical Symbols: Public Information Symbols (ISO 7001: 2007). 2007.” International Standards Organisation (ISO): Geneva, Switzerland.

Jones, Matt, Gary Marsden, Norliza Mohd-Nasir, Kevin Boone, and George Buchanan. 1999. "Improving Web Interaction on Small Displays.” Computer Networks 31 (11). Elsevier: $1129-37$.

Khanom, Sukanya, Anneli Heimbürger, K Tommi, and others. 2013. “Icons: Visual Representation to Enrich Requirements Engineering Work.” Journal of Software Engineering and Applications 6 (11). Scientific Research Publishing: 610.

Knight, Eliot, Charlotte N Gunawardena, and Cengiz Hakan Aydin. 2009. “Cultural Interpretations of the Visual Meaning of Icons and Images Used in North American Web Design.” Educational Media International 46 (1). Taylor \& Francis: 17-35.

Libby, Lisa K, and Richard P Eibach. 2013. "The Role of Visual Imagery in Social Cognition.” The Oxford Handbook of Social Cognition. Oxford University Press, 147.

Lidwell, William, Kritina Holden, and Jill Butler. 2010. Universal Principles of Design, Revised and Updated: 125 Ways to Enhance Usability, Influence Perception, Increase Appeal, Make Better Design Decisions, and Teach through Design. Rockport Pub. 
Ling, Jonathan, and Paul Van Schaik. 2006. "The Influence of Font Type and Line Length on Visual Search and Information Retrieval in Web Pages.” International Journal of Human-Computer Studies 64 (5). Elsevier: 395-404.

Liszka, James Jakób. 1990. “Peirce’s Interpretant.” Transactions of the Charles S. Peirce Society. JSTOR, 17-62.

Liu, Baili, Gavriel Salvendry, and Thomas Kuczek. 1999. "The Role of Visualization in Understanding Abstract Concepts." International Journal of Cognitive Ergonomics 3 (4). Taylor \& Francis: 289-305.

Lodding, Kenneth. 1983. "Iconic Interfacing.” IEEE Comput. Graph. Appl. 3 (2). Los Alamitos, CA, USA: IEEE Computer Society Press: 11-20. doi:10.1109/MCG.1983.262982.

Loizides, Fernando. 2010. "Investigating and Assisting Interactive Document Triage in Electronic Environments.” Bulletin of IEEE Technical Committee on Digital Libraries 6 (1).

Loizides, Fernando, and George Buchanan. 2009. “An Empirical Study of User Navigation during Document Triage." In Research and Advanced Technology for Digital Libraries, 138-49. Springer.

Mack, Arien, Zissis Pappas, Michael Silverman, and Robin Gay. 2002. "What We See: Inattention and the Capture of Attention by Meaning." Consciousness and Cognition 11 (4). Elsevier: 488-506.

Macnab, Maggie. 2011. Design by Nature: Using Universal Forms and Principles in Design. New Riders. 
Marcus, Aaron. 1984. "Icon Design Requires Clarity, Consistency.” Computer Graphics Today 478.

Mavri, Aekaterini, Fernando Loizides, Thomas Photiadis, and Panayiotis Zaphiris. 2014. "We Have the Content... Now What? The Role of Structure and Interactivity in Academic Document Triage Interfaces.” Information Design Journal 20 (3).

McDougall, Siné, and Martin Curry. 2004. "More than Just a Picture: Icon Interpretation in Context." In Proceedings of First International Workshop on Coping with Complexity. University of Bath, 73-80.

Ng, Annie W Y, and Alan H S Chan. 2008. "Visual and Cognitive Features on Icon Effectiveness.” In Proceedings of the International Multiconference of Engineers and Computer Scientists, 2:19-21.

Nielsen, Jakob. 2010. “iPad Usability: First Findings from User Testing.” Jakob Nielsen's Alertbox 26.

—. 2011. "Mobile Content Is Twice as Difficult." Alertbox, Available: Http://www. Useit. Com/alertbox/mobile-Contentcomprehension. Html.

Norman, Donald. 1988. "The Design of Everyday Things.” Doubled Currency.

Norman, Donald A, and Jakob Nielsen. 2010. “Gestural Interfaces: A Step Backward in Usability." Interactions 17 (5). ACM: 46-49.

Ofcom. 2015. Ofcom Adults'media Use and Attitudes Report.

Petocz, Agnes. 1999. Freud, Psychoanalysis and Symbolism. Cambridge University Press.

Preece, Jenny, Yvonne Rogers, Helen Sharp, David Benyon, Simon Holland, and Tom Carey. 
1994. Human-Computer Interaction. Addison-Wesley Longman Ltd.

Rogers, Yvonne. 1989. "Icons at the Interface: Their Usefulness.” Interacting with Computers 1 (1). Oxford University Press: 105-17.

Sadokierski, Zoe Alexandra. 2010. "Visual Writing: A Critique of Graphic Devices in Hybrid Novels from a Visual Communication Design Perpsective.” PhD Dissertation, University of Technology, Sydney.

Sahito, Waqas Ali, Hashim Iqbal Chunpir, Zahid Hussain, Syed Raheel Hassan, and Frederik Schulte. 2015. "Significance of Line Length for Tablet PC Users." In Design, User Experience, and Usability: Users and Interactions, 587-96. Springer.

Sanders, Mark S, and Ernest J McCormick. 1987. Human Factors in Engineering and Design . McGRAW-HILL book company.

Sassoon, Rosemary, and Albertine Gaur. 1997. Signs, Symbols and Icons: Pre-History to the Computer Age. Intellect Books.

Siau, Keng. 2005. "Human-Computer Interaction: The Effect of Application Domain Knowledge on Icon Visualization.” Journal of Computer Information Systems 45 (3). Taylor \& Francis: 53-62.

Stammers, R B, and J Hoffman. 1991. "Transfer between Icon Sets and Ratings of Icon Concreteness and Appropriateness." In Proceedings of the Human Factors and Ergonomics Society Annual Meeting, 35:354-58.

Syarief, Achmad, Jacques R Giard, Thomas Detrie, and Michael K McBeath. 2003. “An Initial Cross-Cultural Survey of User Perception on Web Icon Design for Travel 
Websites." In 6th Asia Design International Conference.

Tognazzini, Bruce. 1992. TOG on Interface. Addison-Wesley Longman Publishing Co., Inc.

Waller, Robert H W. 1980. “Graphic Aspects of Complex Texts: Typography as Macropunctuation.” In Processing of Visible Language, 241-53. Springer.

Ware, Colin. 2010. Visual Thinking: For Design. Morgan Kaufmann.

Yan, Rushan. 2011. "Icon Design Study in Computer Interface.” Procedia Engineering 15. Elsevier: $3134-38$. 


\section{Annexes}

\section{Annex A: Data Tables}

Table A1. List of common and participant discipline/sub-discipline classifications

\begin{tabular}{|c|c|c|c|}
\hline & Discipline & Sub-disciplines & Participant \\
\hline 1 & Medicine and Dentistry & $\begin{array}{l}\text { A100 Pre-clinical Medicine, A200 Pre-clinical } \\
\text { Dentistry, A300 Clinical Medicine, A400 Clinical } \\
\text { Dentistry }\end{array}$ & $\checkmark$ Health science \\
\hline 2 & $\begin{array}{l}\text { Subjects allied to } \\
\text { Medicine }\end{array}$ & $\begin{array}{l}\text { B100 Anatomy, Physiology and Pathology, B200 } \\
\text { Pharmacology, Toxicology and Pharmacy, B300 } \\
\text { Complementary Medicine, B400 Nutrition, B500 } \\
\text { Ophthalmics, B600 Aural and Oral Sciences, B700 } \\
\text { Nursing, B800 Medical Technology }\end{array}$ & $\checkmark$ Biology \\
\hline 3 & Biological Sciences & $\begin{array}{l}\text { C100 Biology, C } 200 \text { Botany, C } 300 \text { Zoology, C400 } \\
\text { Genetics, C500 Microbiology, C600 Sports Science, } \\
\text { C } 800 \text { Psychology }\end{array}$ & $\checkmark$ Psychology \\
\hline 4 & $\begin{array}{l}\text { Veterinary Sciences, } \\
\text { Agriculture and related } \\
\text { subjects }\end{array}$ & $\begin{array}{l}\text { D100 Pre-clinical Veterinary Medicine, D400 } \\
\text { Agriculture, D500 Forestry, D600 Food and Beverage } \\
\text { Studies }\end{array}$ & $\checkmark$ Agriculture \\
\hline 5 & Physical Sciences & $\begin{array}{l}\text { F100 Chemistry, F200 Materials Science, F300 Physics, } \\
\text { F400 Forensics and Archaeology, F600 Geology, F700 } \\
\text { Ocean Sciences, F800 Physical and Terrestrial } \\
\text { Geographical and Environmental Sciences, F840 } \\
\text { Physical Geography }\end{array}$ & $\sqrt{ }$ Physics \\
\hline 6 & $\begin{array}{l}\text { Mathematical and } \\
\text { Computer Sciences }\end{array}$ & $\begin{array}{l}\text { G100 Mathematics, G300 Statistics, G400 Computer } \\
\text { Science, G600 Software Engineering, G700 Artificial } \\
\text { Intelligence }\end{array}$ & $\checkmark$ Computer Science \\
\hline 7 & Engineering & $\begin{array}{l}\text { H200 Civil, H300 Mechanical, H400 Aerospace, H500 } \\
\text { Naval Architecture, H700 Production and } \\
\text { Manufacturing, H800 Chemical }\end{array}$ & $\sqrt{ }$ Civil Engineering \\
\hline 8 & Technologies & $\begin{array}{l}\text { J200 Metallurgy, J300 Ceramics and Glasses, J400 } \\
\text { Polymers and Textiles, J500 Materials Technology }\end{array}$ & $\checkmark$ Visual Arts \\
\hline 9 & $\begin{array}{l}\text { Architecture, Building } \\
\text { and Planning }\end{array}$ & K100 Architecture, K200 Building, K400 Planning & $\checkmark$ Architecture \\
\hline 10 & Social studies & $\begin{array}{l}\text { L100 Economics, L200 Politics, L300 Sociology, L400 } \\
\text { Social Policy, L500 Social Work, L600Anthropology, }\end{array}$ & $\checkmark$ Economics \\
\hline
\end{tabular}


L700 Human and Social Geography

\begin{tabular}{llll}
\hline 11 & Law & M100 Law by geographical area, M200 Law by topic & $\begin{array}{l}\checkmark \text { Law and political } \\
\text { sciences }\end{array}$ \\
\hline 12 & $\begin{array}{l}\text { Business and } \\
\text { Administrative studies }\end{array}$ & $\begin{array}{l}\text { N100 Business Studies, N200 Management, N300 } \\
\text { Finance, N400 Accounting, N500 Marketing }\end{array}$ & $\checkmark$ Finance \\
\hline 13 & $\begin{array}{l}\text { Mass Communications } \\
\text { and Documentation }\end{array}$ & P300 Media Studies, P500 Journalism & $\begin{array}{l}\checkmark \text { Media } \\
\text { studies/journalism }\end{array}$ \\
\hline 14 & $\begin{array}{l}\text { Linguistics, Classics } \\
\text { and related subjects }\end{array}$ & Q100 Linguistics, Q500 Celtic Studies & $\checkmark$ Linguistics \\
\hline & $\begin{array}{l}\text { European Languages, } \\
\text { Literature and related } \\
\text { subjects }\end{array}$ & $\begin{array}{l}\text { R100 French Studies, R200 German Studies, R300 } \\
\text { Italian Studies, R400 Hispanic Studies, R600 } \\
\text { Scandinavian Studies, R700 Russian Studies }\end{array}$ & $\begin{array}{l}\checkmark \text { Translation } \\
\text { Semiotics in French } \\
\text { Language \& } \\
\text { Literature }\end{array}$ \\
\hline
\end{tabular}

Eastern, Asiatic,

African, American and

16 Australasian Languages, T100 Chinese Studies, T500 African Studies

Literature and related

subjects

$\begin{array}{lll}17 & \text { Historical and } & \text { V100 History by period, V200 History by area, V350 } \\ \text { Philosophical studies } & \text { History of Art, V400 Archaeology, V500 Philosophy, } \\ & \text { V600 Theology and Religious Studies }\end{array}$

\begin{tabular}{lll}
\hline & & $\checkmark$ \\
& & Graphic Design \\
Creative Arts and & W100 Fine Art, W200 Design, W300 Music, W400 \\
Design & $\begin{array}{l}\text { Drama, W500 Dance, W600 Cinematics and } \\
\text { Photography, W700 Crafts, W800 Creative Writing }\end{array}$ & Industrial Design \\
&
\end{tabular}

\begin{tabular}{|c|c|c|}
\hline 19 & X100 Training Teachers & $\checkmark$ Education \\
\hline 20 & Combined studies & $\begin{array}{l}\checkmark \text { Library and } \\
\text { museum studies }\end{array}$ \\
\hline
\end{tabular}




\section{Annex B: Image Tables}

Table B1. Spatial representation (position)

\begin{tabular}{ll}
\hline Document Element & Andicative images \\
\hline (a) Main title 'I would draw a centred line segment on the \\
top of an empty document. This is usually \\
where the title is'
\end{tabular}

Table B2. Spatial representation (layout/form)

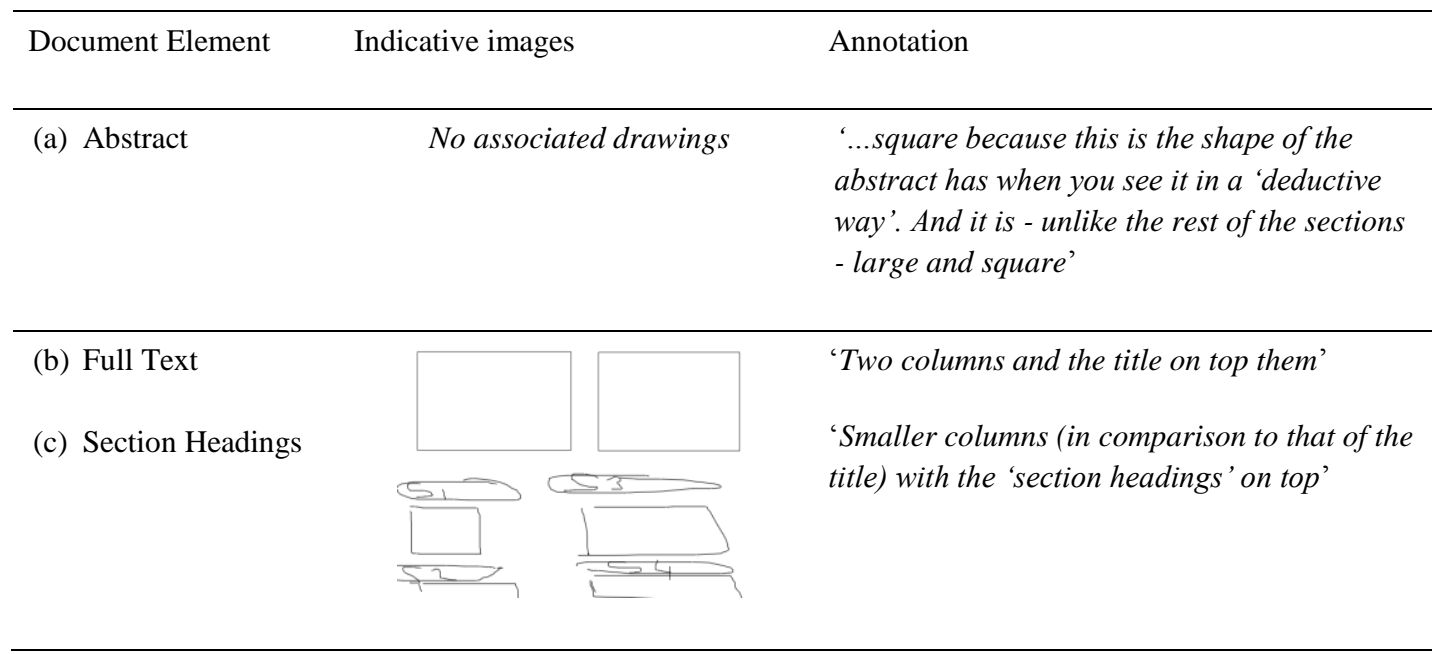


Table B3. Density (line weight)

\begin{tabular}{lll}
\hline Document Element & Indicative images
\end{tabular}
(a) Main title

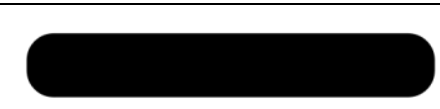
'A large rectangle, at the top of the page, because titles are usually written in large bold fonts'

\begin{tabular}{ll} 
(b) Abstract & $\begin{array}{l}\text { 'Four lines as the user gaze, they read the } \\
\text { first 3-4 lines of abstract and the spaces } \\
\text { between them are big to show that is the } \\
\text { abstract' }\end{array}$ \\
\hline (c) Conclusion & $\begin{array}{l}\text { 'Similar density with the word } \\
\text { introduction* in my previous } \\
\text { drawing......for the word at the beginning } \\
\text { of the caption' }\end{array}$
\end{tabular}

Table B4. Line length

\begin{tabular}{lll}
\hline Document Element & Indicative images & Annotation
\end{tabular}

(a) Full Text $\quad$ '..with lines of varying lengths,
centred, below the main title,

(b) Keywords

'...with small line segments indicating the words'

(c) Section Headings

'Following the logic of representing the title using a thick black line, I would draw smaller and thinner ones for each section heading'

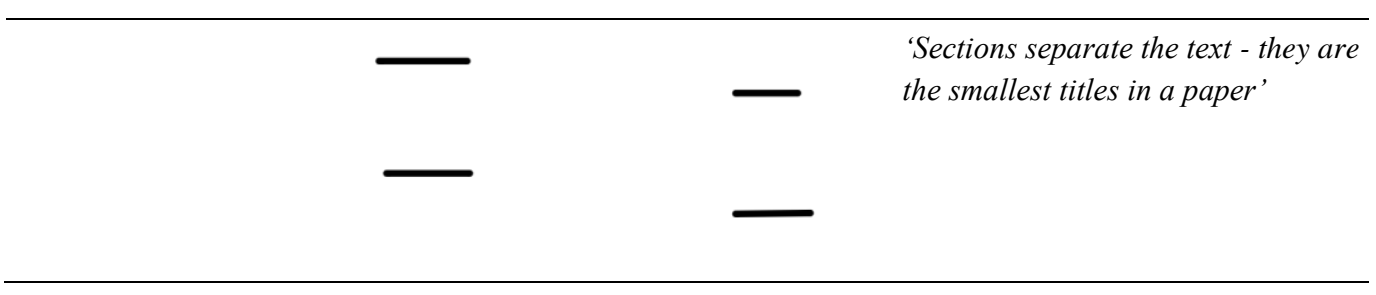


Table B5. Line volume

\begin{tabular}{lll}
\hline Document Element & Indicative images & Annotation \\
\hline Full Text & 'I would draw a rectangle filled with line \\
\hline$\overline{\text { segments indicating the whole document' }}$ \\
\hline
\end{tabular}

Table B6. Anthropomorphic representations: face, human body and bodily parts

\begin{tabular}{|c|c|c|}
\hline Document Element & Indicative images & Annotation \\
\hline (a) Author(s) & & $\begin{array}{l}\text { 'Two human like figures' } \\
\text { 'Two people. One bigger and one smaller } \\
\text { (first and second author)' } \\
\text { 'A human or a face. It would indicate the } \\
\text { people behind the work' }\end{array}$ \\
\hline (b) Full Text & & $\begin{array}{l}\text { 'The main human body, from the neck until } \\
\text { legs...the human body is a semiotic } \\
\text { illustration' }\end{array}$ \\
\hline (c) Conclusion & & $\begin{array}{l}\text { 'The legs ...' } \\
\text { 'An animal's tail' }\end{array}$ \\
\hline
\end{tabular}


Table B7. Anthropomorphic features, external apparel and storytelling

(a) Author

'A hand holding a pen'

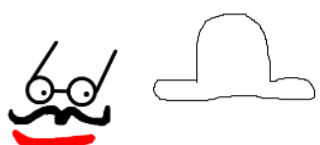

'The brain as from there the idea begins'

'Glasses and moustache for author'

'A hat on top of a well-dressed individual'

(b) Introduction

'A nose smelling a bottle. It's an introduction to the taste'

(c) Conclusion 'Someone talking about what they just drank. It's an overview of the experience, 'Different students each of them wearing a well fit costume'

Table B8. The wise old man, the hero archetype

Document Element Annotation

(a) Introduction

'A man on the podium trying to present his case. The introduction is presenting the justifications and the initiation of the study'

'The gatekeeper standing at the bottom of the hill inside of the new world (with an excited face). The journey is ready to start'

(b) Author

'A teacher and students'

(c) Conclusion

I would draw a judge giving a speech in court, since the judge always speaks at the end of the trial giving his conclusions after hearing everything about the trial' 
Table B9. The house archetype

(a) Introduction "I would draw a door that is opening. This can indicate the introduction to a new space’

'The title is like the 'door' to the world that the academic document"'

(b) Tables 'The windows of a house'

(c) References 'The garden of a house'

Table B10. The tree archetype

Document Element Indicative images Annotation

(a) Introduction

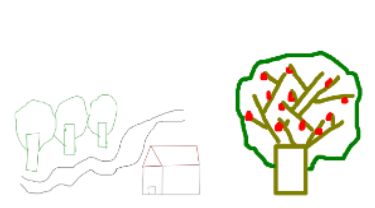

'the whole point of the painting drawing was the apple - so for me it has the outmost importance and it is the essence of the painting'

'I would focus on giving more details'

(b) Full text No image provided

'A new world with drawings capturing for example trees with fruit on them'

(c) Conclusion

'The conclusion from my apple trees'

'A distiller -out of it you get what you really need'

(d) References

No image provided

'Rows of little trees, in the spirit of the of the whole visualization' 
Table B11. Visual homonymy

Document Element Indicative images Annotation

(a) Keywords

'you can put a key-symbol'

'I would draw a key together with small line segments indicating the words;'

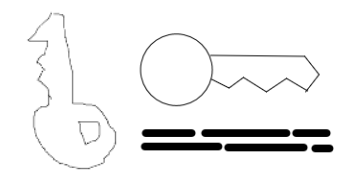

'I would draw keys since 'keywords are specific words that act as keys, as specific clues that can be used to make your search for the relevant subject'

'A key. This 'key' will help people find your article. (sorry for the drawing)'

(b) Tables

'A table'

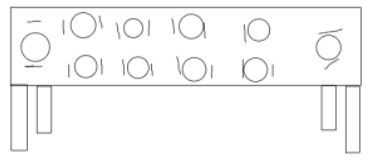

'A drawing table, a table of contents (the contents being the plates and cutlery set on the table)'

Table B12. Linguistic aids (letters and numbers)

\begin{tabular}{ll}
\hline Document Element & Indicative images
\end{tabular}


Table B13. Punctuation

\begin{tabular}{|c|c|c|}
\hline Document Element & Indicative images & Annotation \\
\hline (a) Section Headings & & $\begin{array}{l}\text { 'so the arrow points exactly where someone should } \\
\text { read something' }\end{array}$ \\
\hline & & $\begin{array}{l}\text { 'bullet points for the headings... they summarize } \\
\text { the content of the paper' }\end{array}$ \\
\hline
\end{tabular}

(b) Keywords

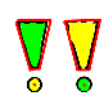

'when you search ... exclamation marks were used again to draw attention'

(c) References

'I would represent them with numbers in brackets,

$[3]$

(d) Abstract which we decide to set apart from the rest...' 
Table B14. Circles in abstract drawings

\begin{tabular}{ll}
\hline Document Element & Annotation \\
\hline & $\begin{array}{l}\text { 'A big circle. This is the main idea } \\
\text { and should be represented in the } \\
\text { title' }\end{array}$ \\
(a) Title & $\begin{array}{l}\text { 'I put the circle to show that research } \\
\text { is something that doesn't stop' }\end{array}$
\end{tabular}

(b) Author
'The brain as from there the idea
begins'
(c) Keywords References
'Representative for the contents of
'the paper'
'I would draw some concentric as important moments'
circles in order to represent the
concentrated knowledge we gain
from the various references we
include in the research'

'A big circle. This is the main idea and should be represented in the

'I put the circle to show that research is something that doesn't stop

'The brain as from there the idea begins'

'Representative for the contents of the paper'

'Triggers as important moments'

'I would draw some concentric present the from the various references we include in the research' 
Table B15. Squares in abstract drawings

\begin{tabular}{ll}
\hline Document Element & Indicative images \\
\hline (a) Abstract & $\begin{array}{l}\text { 'Just like in a painting you get the } \\
\text { whole idea that the artist wants to } \\
\text { transfer in just a square or } \\
\text { rectangular tablet' }\end{array}$ \\
(b) Full text & $\begin{array}{l}\text { 'The descriptive pathway followed by } \\
\text { the authors in presenting the subject } \\
\text { of concern' }\end{array}$
\end{tabular}

(c) References
'Sources for problem definition and
solutions proposed'

'Just like in a painting you get the transfer in just a square or

The descriptive pathway followed by authors in presenting the subject the backbone of the research'

Table B16. Lines in abstract drawings

\begin{tabular}{ll}
\hline Document Element & $\begin{array}{l}\text { Annotation } \\
\text { (a) Author }\end{array}$ \\
(b) Introduction & $\begin{array}{c}\text { 'I would draw a set of diagonal lines } \\
\text { to represent the limits. The word } \\
\text { "author" reminds me Barthes' quote: } \\
\text { "To give a text an author is to impose } \\
\text { a limit on that text" }\end{array}$ \\
\hline (c) Conclusion & 'Towards a place' \\
\hline & 'Overview of the contents of the \\
paper and main contributions'
\end{tabular}


Table B17. Deixis

Document Element $\quad$ Andicative images
(a) Conclusion
$\begin{aligned} & \text { '...indicating that this is the main point where } \\ & \text { everything boils down to' } \\ & \text { 'A thick black arrow heading right' } \\ & \text { 'I would draw a big arrow pointing down in order } \\ & \text { to represent the production of final conclusions } \\ & \text { through a variety of information' }\end{aligned}$

'An arrow pointing to the right in order to visually

(b) Introduction

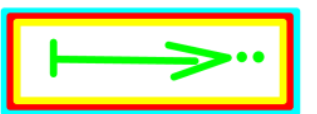
indicate the beginning of the text'

Table B18. Significant acceptance ratings: 12 out of 110 images $(n=<2.5, S D=<0.15$, mode $=1$ or 2$)$ in mean descending order (from 2.0 to 2.5)

\begin{tabular}{llll|l|}
\hline Section \\
headings
\end{tabular}


Table B19. Significant rejection ratings: 43 out of 110 images $(n=>3.5, S D=<0.17$, mode $=4$ or 5$)$ in mean descending order (from 3.5 to 4.5 )
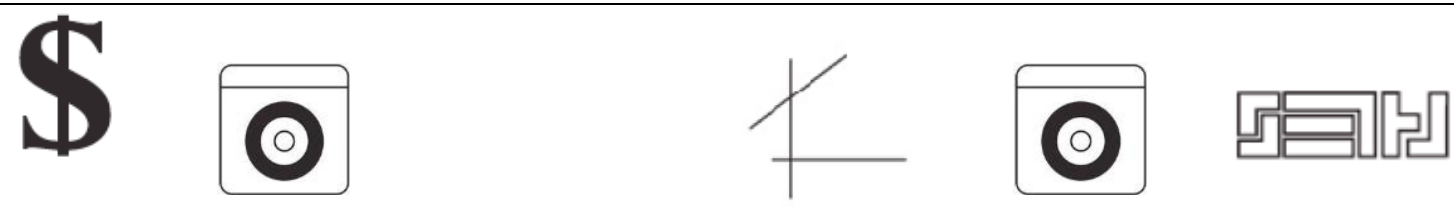

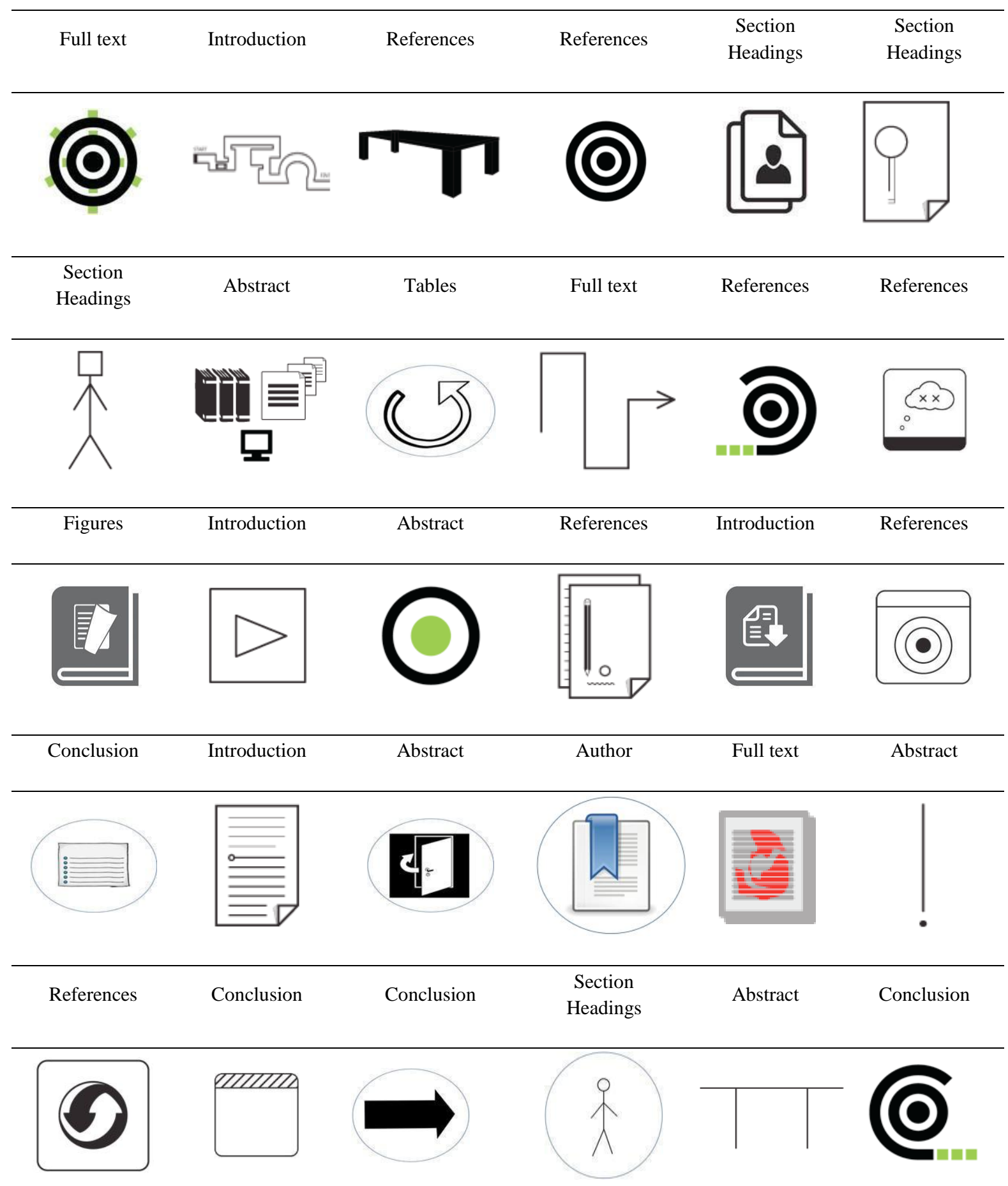




\begin{tabular}{llllll}
\hline Conclusion & Title & Introduction & Author & Tables & Conclusion \\
\hline Keywords & Keywords & References & References & Title & References \\
\hline
\end{tabular}




\section{Annex C: Design Guidelines}

Table C1. Required conditions for Design guidelines

\section{Required conditions:}

\begin{tabular}{l|l}
\hline $\begin{array}{l}\text { 1. Graphical } \\
\text { framework: }\end{array}$ & $\begin{array}{l}\text { Boundaries that delineate the physical area of the paper, acting as a point of } \\
\text { visual reference. }\end{array}$ \\
\hline $\begin{array}{l}\text { 2. Contextual } \\
\text { framework }\end{array}$ & $\begin{array}{l}\text { A perceptible consistent thematic framework to act as a point of conceptual } \\
\text { reference. }\end{array}$ \\
\hline 3. Peripheral elements: & Other peripheral elements to act as relational/comparison factors. \\
\hline
\end{tabular}

Table C2. Design Guidelines

\begin{tabular}{|c|c|c|}
\hline Type: & Guidelines: & Applicable to: \\
\hline Spatial & \multicolumn{2}{|c|}{ An element can be represented by means of Position } \\
\hline \multirow[t]{4}{*}{$\begin{array}{l}\text { Signifies surface } \\
\text { propositions (external } \\
\text { features) }\end{array}$} & $\begin{array}{l}\text { Through: } \\
\text { a. It's distance to the paper boundaries } \\
\text { b. Its spatial relationship with other } \\
\text { elements } \\
\text { Required conditions: } \\
\text { 1. Graphical framework (and/or) } \\
\text { 2. Peripheral elements }\end{array}$ & $\begin{array}{l}\text { Title } \\
\text { (top) } \\
\text { Conclusion } \\
\text { (bottom) }\end{array}$ \\
\hline & \multicolumn{2}{|c|}{ An element can be represented by means of Form } \\
\hline & $\begin{array}{l}\text { In line or solid (fill) mode to resemble the } \\
\text { distinct outline or shape of an element in a } \\
\text { deductive manner. }\end{array}$ & $\begin{array}{l}\text { Abstract } \\
\text { (square) } \\
\text { Full text } \\
\text { (one or two tall columns) } \\
\text { Figures } \\
\text { (rectangle) }\end{array}$ \\
\hline & \multicolumn{2}{|c|}{ An element can be represented by means of Layout } \\
\hline
\end{tabular}




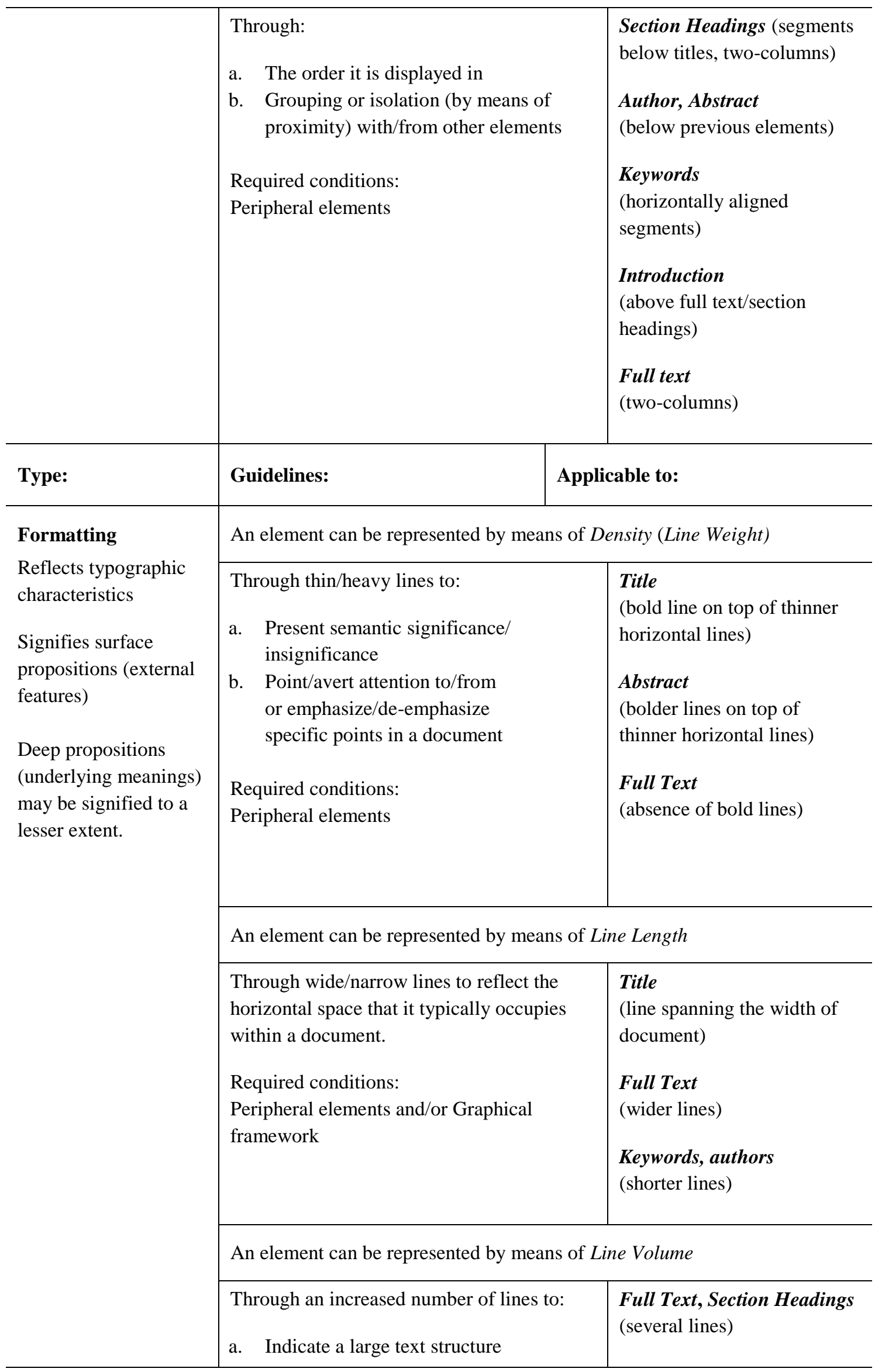




\begin{tabular}{|c|c|c|}
\hline & $\begin{array}{l}\text { b. Point to an isolated segment of } \\
\text { information through extra/less leading } \\
\text { (that is the vertical space between the } \\
\text { lines in a multi-line set) } \\
\text { Required conditions: } \\
\text { Graphical framework }\end{array}$ & $\begin{array}{l}\text { Abstract } \\
\text { (several narrow-spaced lines) }\end{array}$ \\
\hline Type: & Guidelines: & Applicable to: \\
\hline \multirow{4}{*}{$\begin{array}{l}\text { Linguistic aids } \\
\text { Signifies mainly } \\
\text { surface propositions } \\
\text { (external features) } \\
\text { Deep propositions } \\
\text { (underlying meanings) } \\
\text { may be signified to a } \\
\text { lesser extent. }\end{array}$} & \multicolumn{2}{|c|}{$\begin{array}{l}\text { An element can be represented by means of letters as additional recognition } \\
\text { aids }\end{array}$} \\
\hline & $\begin{array}{l}\text { Through the use of: } \\
\text { a. Individual characters i.e. the initials of } \\
\text { the title of an element } \\
\text { b. Combined with illustrative artefacts } \\
\text { such as tables to communicate their } \\
\text { identity }\end{array}$ & $\begin{array}{l}\text { Figures, Tables, } \text { References } \\
\text { (usually as captions) }\end{array}$ \\
\hline & \multicolumn{2}{|c|}{ An element can be represented by means of Punctuation } \\
\hline & $\begin{array}{l}\text { Through the use of: } \\
\text { a. Straight /curly brackets, parentheses, } \\
\text { colons etc. as means of delineating a } \\
\text { specific text segment/element in the } \\
\text { document. } \\
\text { b. Bullets, numerals etc. to depict } \\
\text { serialized information } \\
\text { c. Exclamation marks to illustrate the } \\
\text { importance of an element by means of } \\
\text { stylization. } \\
\text { Required conditions: } \\
\text { Graphical framework and/or Peripheral } \\
\text { elements }\end{array}$ & $\begin{array}{l}\text { Abstract } \\
\text { (brackets) }\end{array}$ \\
\hline Type: & Guidelines: & Applicable to: \\
\hline \multirow[t]{2}{*}{ Visual Homonymy } & \multicolumn{2}{|c|}{ An element can be represented by means of Visual Homonymy } \\
\hline & $\begin{array}{l}\text { Through the depiction of the visual } \\
\text { characteristics of a homonym, which is a } \\
\text { physical object - as opposed to the original } \\
\text { object - which is an abstract or a semi- } \\
\text { abstract element. }\end{array}$ & $\begin{array}{l}\text { Keywords } \\
\text { (key) } \\
\text { Tables } \\
\text { (table) }\end{array}$ \\
\hline
\end{tabular}




\begin{tabular}{|c|c|c|}
\hline Type: & Guidelines: & Applicable to: \\
\hline $\begin{array}{l}\text { Iconic } \\
\text { representations with } \\
\text { symbolic meaning } \\
\text { (iconic-symbolic) }\end{array}$ & \multicolumn{2}{|c|}{ An element can be represented drawing from archetypal forms } \\
\hline $\begin{array}{l}\text { Signifies deep } \\
\text { propositions } \\
\text { (underlying meanings) } \\
\text { through the depiction } \\
\text { of surface } \\
\text { propositions. }\end{array}$ & $\begin{array}{l}\text { Invites for a large number of conceptual } \\
\text { design approaches; strictly requires that the } \\
\text { conditions below are present. } \\
\text { Suggestions include the use of: } \\
\text { a. Anthropomorphic forms/parts, related } \\
\text { apparel to indicate both external as well } \\
\text { as conceptual values. } \\
\text { Required conditions: } \\
\text { Graphical framework, Contextual } \\
\text { framework and/or Peripheral elements. }\end{array}$ & Applies to all elements \\
\hline Type: & Guidelines: & Applicable to: \\
\hline Abstract & \multicolumn{2}{|c|}{ An element can be represented by means of abstract shapes and lines } \\
\hline \multirow[t]{3}{*}{$\begin{array}{l}\text { Signifies deep } \\
\text { propositions } \\
\text { (underlying meanings) } \\
\text { through the use of } \\
\text { archetypal shapes, } \\
\text { lines and the } \\
\text { phenomenon of deixis. }\end{array}$} & $\begin{array}{l}\text { Through the use of basic shapes: } \\
\text { a. Circle: to imply concentration and } \\
\text { enclosure of information, focal point, } \\
\text { continuity. } \\
\text { b. Square: to imply stability, security, } \\
\text { completeness (enclosing information). } \\
\text { c. Lines: to imply a path, direction, to join } \\
\text { various shapes together. } \\
\text { Required conditions: } \\
\text { Contextual framework and/or Peripheral } \\
\text { elements. }\end{array}$ & $\begin{array}{l}\text { Abstract, Conclusion } \\
\text { (circle: summary of contents, } \\
\text { focal point) } \\
\text { Title, References } \\
\text { (circle: main idea, } \\
\text { concentrated knowledge) } \\
\text { Full text } \\
\text { (square: descriptive pathway, } \\
\text { the solution ) } \\
\text { Introduction, Conclusion } \\
\text { (lines: towards an outcome, } \\
\text { overview/segmentation of } \\
\text { contents) }\end{array}$ \\
\hline & \multicolumn{2}{|c|}{ An element can be represented by means of deictic devices } \\
\hline & $\begin{array}{l}\text { Through the use of arrows: } \\
\text { a. To imply the location or the flow of } \\
\text { information } \\
\text { b. To direct attention to a specific spot } \\
\text { within the document. } \\
\text { c. To imply the deeper meaning of the } \\
\text { arrow (i.e. leading to an outcome) }\end{array}$ & $\begin{array}{l}\text { Conclusion, Introduction } \\
\text { (towards the end of the } \\
\text { document, up towards the } \\
\text { beginning of the document) } \\
\text { Keywords } \\
\text { (importance) } \\
\text { Conclusion } \\
\text { (towards an outcome/result) }\end{array}$ \\
\hline
\end{tabular}


